\section{Very Rural Background: \\ os desafios da composição-terra \\ da África do Sul e do Zimbábue \\ à chamada Educação Superior}

DOI

http://dx.doi.org/10.11606/ 2179-0892.ra.2020.178183

\author{
Antonádia Borges \\ Universidade de Brasília | Brasília, DF, Brasil \\ antonadia@gmail.com |https://orcid.org/0000-0002-2403-8869
}

RESUMO

Este artigo traz algumas considerações de ordem analítica e políticas sobre o processo de zumbificação ou embruxamento na universidade e nas promessas de uma educação superior. $\mathrm{O}$ artigo ancora-se em material diverso (fragmentos de uma biografia, diários de campo da vida acadêmica e romances literários), proveniente de pesquisa na África do Sul e no Zimbábue. O argumento etnográfico tem duas interlocutoras principais que defendem o que chamamos de uma composição-terra. Elas lutam para se desvencilhar do aniquilamento colonial e racista que restringe suas vidas ao que denominamos de composição-plantation. Suas considerações sobre como o humano é reduzido a mero human resource na universidade, na educação superior e além, conformam argumentos etnográficos com força para confrontar a devastação capitalista promovida em nome de um sujeito universal de conhecimento. A principal proposta do artigo é, portanto, uma transformação analítica dos conceitos de alteridade, igualdade e diferença.

Very Rural Background: South Africa and Zimbabwe's

Land-Composition Challenging the So-Called Higher Education

ABSTRACT Drawing from various sources (fragments of biography, diaries of my own academic life, literary novels) the article aims to deepen the hypothesis that ethnography is a necessary condition for life against plantation as a destructive matter in countries like South Africa and Zimbabwe. Devoted to tackling with the process of capitalist zombification or bewitching, our interlocutors understand the university and its promises of higher education as challenges to their land-composition. The main proposal of the article is, therefore, an analytical transformation of the concepts of otherness, equality and difference in order to challenge university itself as a plantation driven by the exploitation of human resources.

África do Sul, Zimbábue, Tsitsi Dangarembga, Educação superior, Plantation, Terra, fallism

KEYWORDS

South Africa, Zimbabwe Tsitsi Dangarembga, Higher Education, Plantation, Land, fallism 
Para Sam Moyo (in memoriam)

\section{INTRODUÇÃO}

É pouco usual entre cientistas sociais brasileiros ter passado algum tempo de suas vidas no sul do continente africano, especialmente na África do Sul e no Zimbábue'. Em ambos os países, embora os projetos de pesquisa nos quais me envolvi pessoalmente tivessem outros objetos, acabei, por força das circunstâncias, frequentando instituições de ensino superior e vivenciando muito de perto o cotidiano de acadêmicos locais, com docentes ou estudantes. Em se tratando de países com experiências coloniais resumidas na fórmula settlercolonialism, a convivência acadêmica se dá não somente entre locais, mas entre locais e estrangeiros de diversas procedências, com a língua inglesa mediando suas transações.

O tipo de colonialismo que marca as experiências históricas desses países não poupa seu ambiente acadêmico. Temos aqui um bom objeto para pensar nesta existência dupla da ciência ou da vida acadêmica como universal e também, concomitantemente, como particular, marcada pelas veleidades locais. Vivemos tal dilema continuamente: por um lado, cremos poder dialogar cruzando fronteiras nacionais porque nosso solo comum é a área de pesquisa e de ensino a que nos dedicamos, mas por outro, temos plena consciência de que os contextos e cotidianos locais de produção e propagação desses conhecimentos imprimem inflexões cruciais em seus movimentos. No sul do continente africano, a despeito de um enquadramento mandatório relativo ao apartheid e ao racismo de Estado, quando "redescobrimos o ordinário", como sugere Njabulo Ndebele, atentamos para dimensões da existência incomensuráveis e dificilmente contidas na narrativa mestra².

Assim, jamais será possível esgotar a miríade de variações que dão a cara local de cada universo acadêmico, isto é, nunca chegaremos a reduzir o debate a um plateau inamovível de discussão. Toda a tinta que já se deitou a propósito da história da vida acadêmica nesses contextos atravessados pelo apartheid é prova disso: desde aquelas voltadas ao entendimento dos trânsitos acadêmicos entre norte e sul, quando do estabelecimento local dessas instituições, até as pesquisas que indicam a centralidade do persistente escrutínio europeu sobre a vida intelectual no sul global. Entre as coordenadas que sigo neste mapeamento efêmero do fenômeno aqui discutido está a importância crucial da aprovação internacional das agendas e dos produtos acadêmicos produzidos localmente, por sua vez, lastro crucial para a garantia de investimento pecuniário nas instituições e em seus projetos. Esta aprovação chancelada por agências dotadas de sistema que atestam qualidade se traduz

2 | Njabulo Ndebele é um intelectual sul-africano que, entre outras posições, foi reitor da Universidade de Cape Town. Ao analisar a produção literária sul-africana, chamou atenção para a importância de se "redescobrir o ordinário". Há grande similaridade entre a proposta política e estética de Ndebele e a que vemos no trabalho de Veena Das (2006), a qual por sua vez encontra forte inspiração nas meditações de Stanley Cavell. Em todos esses escritos, vemos insurgir-se a resistência transformadora nas bordas do que é reconhecido, nas fraturas, no desdenhado. Atentar para essas experiências é o caminho intelectual ao encontro do que ao existir nos conclama a abdicar do chavão e a experimentar o inusitado. em financiamento (advindo do capital global) e também em avaliações que catapultam algumas instituições sul-africanas a degraus de legitimidade que garantem 
inversões futuras de capital, numa espécie de círculo virtuoso.

Um dos aspectos apontados pela literatura diz respeito ao equilíbrio precário possível de ser alcançado em meio a essas demandas tão distintas: por um lado, a eficiência da produção acadêmica para o capital e, por outro, o papel que se espera das instituições de ensino superior, em contextos marcados pelo colonialismo, de enfrentar o fardo do racismo e da desigualdade. Diante de tal aporia, torna-se imperativa uma transformação analítica dos conceitos de alteridade, igualdade e diferença, capaz de efetivamente desvencilhar a universidade de sua composição-plantation, ou seja, de sua existência predadora de um Outro constituído para fins de perpetuação dos próprios meios de produção - que se tornam inquestionáveis - e sua principal mercadoria, ou seja, as instituições de pesquisa e ensino superior e o conhecimento para a expansão capitalista.

Para tratar igualmente da heterogeneidade local em relação a essa política de feição e funcionamento tão complexos, de múltiplas escalas e magnitudes, começo este artigo recuperando o que seria uma credencial, que ouvi pronunciada em Harare. Nossos colegas acadêmicos, por meio de uma corruptela, um acrônimo, se referiam a certa pessoa do mesmo meio não como VIP3 mas como VRB ${ }^{4}$, isto é, alguém com um Very Rural Background. Em decorrência da recente segregação espacial

3 | Pronuncia-se /vraipi/

4 | Pronuncia-se /vubi/ que Ihes impunha a residência mandatória na cidade ou na roça e, consequentemente, seu trânsito constante, muitas vezes clandestino, entre um e outro lugar, para se encontrar com parentes ou para se abrigar junto a familiares distantes, não é equivocado afirmar que praticamente todas as pessoas negras têm um rural background. VRB refere-se aqui a algo mais específico, a um traço que distingue uma distinta disposição intelectual diante da vida acadêmica, sua razão de ser e seus valores. Para tratar desse sentido mais recôndito, na próxima seção do artigo apresento as reflexões de Archie Mafeje e Franz Fanon acerca da produção desta alteridade "rural" e seu efeito similar à loucura ou ao embruxamento.

\section{À LUZ DE MAFEJE E FANON}

Rural, neste contexto, como disse Archie Mafeje em textos etnográficos do final dos anos sessenta, ou melhor, ter um very rural background, implica uma existência outra, outra ontologia, desafiadora e, por essa razão talvez, como para meus amigos mencionados acima, indicador de uma diferença não menosprezável, ora suscitando escárnio ora até mesmo desprezo. Mafeje constrói analiticamente este problema a partir de seu trabalho de campo para um estudo etnográfico acerca da violenta relação entre racismo de Estado (apartheid), segregação espacial e processos de diferenciação interna na township de Langa. Esta township, como as demais, era uma espécie de conjunto habitacional de traçado modernista com fins explícitos de segregação espacial, violentamente erguido e mantido pelo e para o racismo de Estado. Embora 
a nomenclatura township perdure até hoje para áreas urbanas periféricas, à época da pesquisa de Mafeje, para Langa tinham sido removidas e nela confinadas pessoas classificadas pelo regime do apartheid como black, as quais não tinham direito à propriedade de suas casas (Borges, 2011).

Especialmente a partir do Croup Area Act de 1950, que legislava sobre a segregação espacial da população em áreas determinadas e separadas, a partir da sua classificação racial, negros que viviam em áreas no interior do país ou mesmo em cidades, destinadas somente a brancos, passaram a ser confinados majoritariamente nos bantustões ou homelands, isto é, em áreas rurais precárias destinadas à população classificada como bantu (Mabin, 1991). Diante da arbitrariedade dessas remoções forçadas, produziu-se por parte do Estado uma dinâmica de diferenciação social que tencionava promover um esfacelamento dos elos entre cidade e roça, a partir da oposição entre o mundo moderno da township e o atraso material e cultural da homeland.

A tal propósito, dois artigos seus se destacam como desdobramento da obra principal, publicada em livro, em coautoria com Monica Wilson. Tanto em A chief visits Town quanto em The role of the bard in a contemporary African community, Mafeje explora a produção do caráter abjeto dos conhecimentos do chefe e do bardo. Para Mafeje, a produção de sua obsolescência por meio do epíteto tradicional produz-se em concomitância com o esfacelamento humano que a vida urbana e segregada exigia. Em uma township como Langa, constituía-se uma diferenciação interna entre os mais coerentes com o modernismo racista e seu modo de reconhecer a existência do negro e aqueles com maiores dificuldades de se adaptarem ao presente ou ao lugar, em suma, ao tempo e ao espaço que lhes era consignado pelo governo nacionalista e racista. Estes últimos, ao crerem no chefe tradicional ou se mesmerizarem diante do encantamento poético do bardo, revelariam estar indefectivelmente aprisionados por não refutarem tais representantes e tais representações, ignorando sua serventia para os propósitos do regime (Ntsebeza, 2005). Aos demais, mais fluentes nas línguas coloniais (inglês e africâner) e nos costumes citadinos, seriam atribuídas, também pelos brancos, por mais irônico que isso seja, mais racionalidade e razoabilidade. Nosso autor revela, em sua construção etnográfica, que ao invés disso, súditos - na cidade ou na roça, na township ou na homeland — não ignoram as veleidades do poder dos chefes (tradicionais ou modernos), ao contrário do que afirmam os que criticam sua alienação. De maneira oposta, afirmam, em réplica política, que a suposta autonomia dos sujeitos aspirantes do exclusivamente moderno seria ela sim um sinal de sua absoluta privação de razoabilidade (Mafeje, 1962 e 1967). O debate proposto por Mafeje segue vivo ainda hoje e um de seus palcos mais inflamados é a universidade, onde se desenrolam embates sobre a vida acadêmica e a educação superior.

No universo acadêmico que nos foi dado conhecer na África do Sul e, mais timidamente, no Zimbábue, pode-se dizer que, a despeito do empreendimento científico pelo entendimento, há imensa dificuldade em acolher devidamente os 
sujeitos com VRB, ou seja, em abrir mão do fetiche colonial da integridade, da coerência, da perenidade - qualidades que, como vemos quando de sua pronúncia, são, ao contrário, inerentemente positivadas, intrinsecamente impossíveis de ser contestadas. Não seria exagerado dizer que para nossos colegas acadêmicos refutá-las implicaria praticamente enlouquecer.

$\mathrm{NaÁfrica} \mathrm{doSul,} \mathrm{não} \mathrm{foram} \mathrm{poucos} \mathrm{os} \mathrm{relatos} \mathrm{sobre} \mathrm{estudantes} \mathrm{que} \mathrm{mais} \mathrm{faltam}$ do que vão às aulas, porque sempre um parente seu está sendo enterrado em algum lugar ermo e distante no interior do país. Uma amiga próxima, vinda da Europa, disse-nos exasperada que nunca esperou se deparar com tantos atestados de óbito, trazidos pelos estudantes, para justificar suas faltas. Outro colega lamentou em tom de comiseração uma pesquisa que indicava os números da desnutrição entre os estudantes universitários de seu campus. Ele, também branco, sabia, mas recusava-se a acreditar que dava aulas para pessoas que como qualquer trabalhador negro do país, se alimentava, quando muito, de um pacote de pão de forma, dividido em duas partes, uma comida pela manhã e outra pela noite. A despeito dessas evidências, por assim dizer empíricas, e do fato de esses meus interlocutores cientistas sociais se empenharem para não pronunciar muito prontamente juízos acerca da irracionalidade ou da falta de compromisso com a vida acadêmica comme il faut, a cesura ainda os orientava como condição sine qua non para se estar no mundo acadêmico. $E$ não só isso, entendiam sua estupefação como resultante de seu enfrentamento ao legado colonial que havia forjado crenças e práticas familistas e despóticas. Eles se perguntavam de maneira genuína: Diante da avassaladora destruição, ou se quiserem minimizar, transformação na vida indígena imposta pelo colonialismo, como é possível que algumas pessoas sigam sendo atormentadas por ancestrais, promovendo rituais para apaziguá-los, retornando periodicamente a vilarejos longínquos e, com isso, quebrando sua imersão na cidade, na modernidade, no capitalismo?!

Sua observação parte sem dúvida de um ponto de vista ou, igualmente, de uma crença segundo a qual haveria, supostamente, quem não se desviasse da linha de ascensão dos valores e conceitos modernos. Em suma, para sujeitos sem fraturas, sem dissenso, a captura absoluta teria ocorrido e dela teria resultado uma existência, embora penosa, ao menos coerente. Aos demais, a alienação ou, no limite, a insanidade, o que muito os preocupava.

Se lembrarmos, no entanto, as reflexões de Frantz Fanon, entre tantos outros, os troubles mentaux indicariam a um só tempo uma enfermidade, mas também uma reação ao olhar colonial sobre si como Outro. A psicanalista Alice Cherki (2016) recorda-nos que ainda hoje persiste o que Fanon chamou de efeito de sideração (l'effet de sidération). O Outro não é um duplo do sujeito colonizador, na medida em que nenhuma imagem positiva Ihe é atribuída e, no limite, nem sequer a condição de humano lhe é franqueada. Mais contemporaneamente, o papel político da escuta psicanalítica diante da violência colonial segue sendo reivindicado por intelectuais 
como Grada Kilomba (2008). Para ela, a reiterada posição marginal do Outro do sujeito branco indica o racismo como fundamento das constituições psíquicas contemporâneas. Nesta chave, ao contrário do percebido acima, uma existência coerente seria uma não existência, ou uma existência muito distante daquilo que, nos termos novamente de Mafeje, seria uma ontologia combativa:

\footnotetext{
Uma de suas dimensões fundamentais [da ontologia combativa] é reconhecer a validade e a inteligibilidade de toda experiência, a despeito de um referencial, um olhar, uma lógica ou uma apreciação que lhe sejam exteriores. [Sua] proposta abdica da relação de entendimento entre diferenças, de maneira heurística, pois em tal relação de produção de conhecimento somente um dos polos se mostra enigmático e sob investigação: o do Outro, como suporia a ideia de alteridade. (Borges, 2015).
}

A crítica ao exaustivo trânsito entre roça e cidade, entre mundos dos vivos-vivos e dos vivos-mortos, entre universidade e extramuros, mais que uma admoestação liberal de esquerda, indicaria um preocupante elogio às rupturas, aos persistentes esquecimentos coloniais que autores como Fanon e Mafeje viram pelo avesso.

\section{QUE CORPO INTERESSA À PLANTATION?}

O esbulho em nome do desenvolvimento reedita-se a cada dia como missão civilizatória: acumulação primitiva animada pela aniquilação de tudo o que se entende como primitivo (Moyo, 2011). O estrito interesse no trabalho como produção e reprodução tende a excluir de nosso campo de atenção muito da ação performática que nos constitui, contribuindo assim para a irrelevância de tudo o que não tem valor imediatamente reconhecido, em outras palavras, para a obliteração de tudo o que (ainda) não tem ou gera valor, perdido que está nas fendas do cotidiano que mencionamos acima. É neste sentido que a universidade, a indústria da educação superior, assemelha-se a uma plantation, para a qual só interessam os atributos dos sujeitos nela engajados que sirvam para incrementar a extração e o acúmulo de riquezas ou resources ou, como se discutirá mais adiante, sua existência como human resources (Oaks, 1977).

Alguns leitores objetarão clamando por uma atenção ao que foge desta definição por demais genérica, acachapante até, da universidade como plantation ou da composição-plantation da universidade. A constatação crítica da qual comungamos encontra suas bases, no entanto, em argumentos e discursos sobre o corpo, que orientam e determinam as percepções hegemônicas sobre quem constitui a humanidade e quem não importa, isto é, os dispensáveis, mas mais predominantemente AS dispensáveis, frequentemente despejadas e torturadas fora dos espaços passíveis de escrutínio público (Povinelli, 2011:22). O corpo da mulher como colônia ou a colônia como corpo de mulher (como sustenta Alice Walker em The Color Purple, 1982, 
ou em Possessing the Secret of Joy, 1992) constitui o arquivo colonial por excelência, que se quer perscrutar sem mesuras, não raro ao limite de sua aniquilação (Derrida, 2008). Nele se revela a violência intrínseca aos dualismos modernos, especialmente à noção de fetiche - tão central no entendimento clássico do capitalismo - que, por sua vez, remete ao alcance cognitivo parcial que teriam os indígenas acerca do que verdadeiramente "animaria" as coisas do mundo (Matory, 2018).

$\mathrm{Na}$ África do Sul, as raízes coloniais e racistas da universidade são indiscutíveis, no entanto, diferentemente do que se passou no Zimbábue, especialmente nos anos 2000, após a chamada "radicalização do Estado" (Moyo e Yeros, 2007), a transição pós94 não almejou rupturas com o capital. A universidade, embora pública, nunca foi exclusivamente estatal naquele país e, para sua continuidade, os fluxos financeiros habituais não poderiam deixar de alimentá-la. A contemporização como condução política impediu por princípio que vozes dissidentes internas - dos rincões do país — se fizessem ouvir sob pena de "pôr tudo a perder"; por isso, protestos estudantis como aqueles tão rememorados dos sangrentos tempos da luta antiapartheid foram desaconsel hados em nome da democracia e da nação reconciliada. Ao invés de protestar como antes, as organizações estudantis passaram a ter assento nas estruturas gerenciais das universidades, onde entenderiam que não havia mais um governo ao qual fazia sentido se opor e que a irreconciliável contradição entre os interesses do capital e as demandas de estudantes excluídos precisaria de muito tempo para ser resolvida (Cele, 2009).

A estabilidade econômica alcançada pelo país tornara de certa forma essa orquestração praticamente irrefutável durante as primeiras duas décadas do pós-apartheid. O movimento político estudantil mais recente, conhecido como fallism, emerge de maneira multifacetada, mas apontando para uma constatação comum: o edifício da universidade seguiu com suas estruturas de privilégio inalteradas, rentável como sempre e com qualidade inabalada, graças ao desprezo pelas demandas por uma sociedade mais igualitária e verdadeiramente antirracista (Jansen, 2017). Até este levante em massa, inúmeros e mesmo volumosos protestos ocorreram ao longo de vinte anos na África do Sul pós-apartheid, mas suas causas foram invariavelmente minimizadas, por se tratar de demandas pontuais e autorreferenciadas, resumidas ao problema de clientes economicamente vulneráveis sem condições de pagar para estudar (as "fees"). Às manifestações de 2014 contra o legado colonial que deu corpo ao movimento \#rhodesmustfall se somaram a outras que em 2016 desaguaram no mais amplo \#feesmustfalls:

Not only did students wage a struggle about fees, which directly affected them and their parents, they also joined forces with university-based workers who had been fighting their own battles of being "outsourced" since neoliberal principles of managerialism were introduced at South African universities in the late 1990s. (Ntsebeza, 2016: 934).
5 | Na virada dos anos 2010, os indexadores das publicações em plataformas como o Twitter se tornaram formas de ação política, desde então conhecidas como ativismo de hashtag. Bonilla e Rosa (2016) defendem que o protesto digital convida ao que chamam de hashtagethnography. No ano de 2015 , os protestos dos estudantes universitários na África do Sul foram etiquetados inicialmente com a hashtag \#rhodesmustfall e, em seguida, com \#feesmustfall. Para uma análise comparativa de reivindicações de estudantes universitários em contextos como o da África do Sul no pós-apartheid, ver Neves et al. (2019). 
O chamado fallism, em suas muitas variantes, reivindicou-se representativo dessas inúmeras demandas silenciadas, que não alcançavam o status de causa coletiva defendida pelos representantes estudantis nas instâncias institucionais legítimas no pós-apartheid. De todos os modos, como outrora, aparentemente nem sequer o fallism acolheu as demandas sem verdadeira refutação epistêmica, como aquelas das pessoas com very rural background.

\section{O FARDO DE UM VERY RURAL BACKGROUND}

Nos muito distintos lugares em que faço pesquisa, volto-me para os enredamentos crescentes no capitalismo e sua íntima relação com a luta por um lugar para viver, seja como vivo ou morto (Borges, 2011; 2018; 2020). Chamam minha atenção analítica os engajamentos políticos e teóricos das pessoas com quem faço pesquisa em ir contra sua obliteração, seu apagamento no espaço, em suma, em ir contra certo tipo de morte (matada ou em vida). A principal pessoa para as reflexões reunidas neste artigo é Sibongile Khubeka, neta de Mangaliso Khubeka, notória liderança do Landless Peoples Movement, quando começamos a fazer pesquisa em Kwazulu-Natal, nos idos de 2007 (Rosa, 2011).

Conhecemos Bongiwe, como é também chamada, quando era uma criança e ia para a escola na township de Madadeni, usando o uniforme de desenho colonial, como todas as outras, em uma língua que não usava em seu cotidiano: o inglês. Após a morte de sua mãe, ela foi já adolescente para a casa do avô na township de Thokoza (Gauteng), a mesma em que nascera e de onde se mudara quando era um bebê após o assassinato de seu pai no fim dos anos 90 (Donham, 2011). Em uma das ocasiões em que nos encontramos, ela estava estudando ciências da computação em regime semipresencial na Universidade de Johanesburgo, enquanto trabalhava na empresa aérea Mango, como comissária de bordo. Nenhuma das ocupações perdurou. Na última vez que a vi, em 2018, estava de volta à Kwazulu-Natal, vivendo na fazenda que seu avô recebera no processo de redistribuição, no vilarejo rural de Ingogo. Em seus braços, um bebê, cujo pai, como todos os homens, não passava de um inja ou cachorro' .

$\mathrm{O}$ que mais a ressentia, no entanto, era o fato de ter descoberto que nem na Universidade nem na Mango fora aceita como era, isto é, com obrigações rituais para com seus ancestrais, que exigiam dela periódicos pedidos de licença. A partir de um complexo entramado de atribuições relacionadas tanto à descendência quanto à aliança, Bongiwe se constituiu ao longo da vida como elemento imprescindível em grande parte das cerimônias rituais conduzidas por seus familiares. Para seguir em paz com sua existência, seus planos de continuar estudando, de viajar pelo mundo, ela precisava periodicamente fazer-se presente na terra onde jaziam seus ancestrais. Ao invés de ser entendida como vital para seu sucesso na cidade também conhecida como Eldorado (Egoli), sua ausência da plantation urbana fez dela, inicialmente, alvo
6| Em Borges (2017), a partir de um exercício de aproximação entre material etnográfico e romances de ficção, especialmente a partir da obra de J.M. Coetzee reflito sobre como na África do Sul, os discursos racistas e de ódio lançam mão de propriedades associadas aos cachorros para esvaziar de humanidade as pessoas mencionadas nas analogias. 
de escárnio e, ao fim, dada sua resistência em ceder à cesura, um ser dispensável. Em vez, porém, de assumir como verdadeira ou real a afirmação colonial sobre sua existência, Bongiwe devolveu aos seus detratores o diagnóstico que dela tinham feito, ao me dizer que "na cidade não havia espaço para pessoas, somente para zumbis".

Torna-se inevitável neste momento um détour para recuperarmos a obra de dois autores sul-africanos centrais para os mais contemporâneos debates em teoria antropológica, cuja matéria para reflexão é justamente o fenômeno da zumbificação. A principal tese dos Comaroff assenta-se sobre um engajamento liberal de esquerda, amparado em um quadro analítico de inspiração marxista. É preciso esclarecer que tal posição não é prerrogativa de ambos, mas um solo comum onde colocam firmemente seus pés diversos intelectuais brancos que se dedicam a lutas antirracistas, interessados na "natureza da consciência histórica" naquele país, como os colegas que mencionei na abertura deste artigo (Comaroff \& Comaroff, 1987). Em suas análises, com grande atenção ao dado etnográfico, os autores indicam que ideologias de semblante nacionalista perderam espaço para uma nova mercadoria: as reivindicações identitárias, tornadas promessas de liberdade e autorrealização. $A$ possibilidade de consumir sem emprego formal e sem remuneração decente suscita rumores acerca de quem o consegue, tanto pela abjeção branca e liberal ao consumo conspícuo, quanto pela ojeriza despertada pela suspeita de apropriação de um meio de produção abjeto: um cadáver zumbificado (Comaroff \& Comaroff, 1999).

$O$ argumento dos autores se desdobra em uma frente pouco contestada, que chegou a suscitar comissões de inquérito para apurar eventos violentos de matiz xenofóbico: em meio à escassez de emprego, aos estrangeiros ou makwerekwere são destinadas as suspeições e as mais violentas represálias (Pereira, 2016). Diante do que diagnosticam como violência epidêmica, os autores alertam para a necessidade de ação ou intervenção estatal como reguladora dos efeitos "concretos" que a crença em "quimeras" não deixa de produzir.

Taussig estabeleceu uma relação entre alienação e plantation que comunga de premissas similares às dos Comaroff. Para Taussig, a magia pode reforçar a consciência crítica, mas também criar, entre os trabalhadores, divisões e "crippling conformism" (Taussig, 1980: 230). Fanon equivocadamente tomaria uma realidade hipotética, possível, mas não real, como "undoubted reality" ${ }^{7}$. Após citar Fanon, Taussig sentencia: "surely this is exaggerated-a blind belief in the blind belief of the primitive (Taussig, 1980: 230).

Diversamente do que depreende Taussig do parágrafo retirado de Os condenados da terra, Bongiwe parece reiterar Fanon, ao esclarecer explicitamente que para além do provimento constante de energia para o Capital, há uma vida. E mais, que a figura do zumbi não se restringe àquela da vida drenada pelo Capital, pelo Colonialismo. Bongiwe reflete sobre uma vida que passa ao largo do aprisionamento da plantation, da restrição à linha: uma vida marcada por movimentos a esmo, pelo

7| Este é o trecho citado por Taussig, em tradução brasileira: "A atmosfera de mito e magia, causando-me medo, comporta-se como uma realidade indubitável. Aterrorizando-me, ela me integra nas tradições, na história de minha região ou de minha tribo, mas ao mesmo tempo me tranquiliza [...] Quando me enredo nessa teia inextricável onde os atos se repetem com uma permanecia cristalina, é a perenidade de um mundo meu, de um mundo nosso que dessa maneira se afirmar. Os zumbis, acreditai-me são mais terrificantes do que os colonos"(Fanon, 1968: 42). 
inusitado, pela criatividade e pela transformação. Movimentos esses normalmente por nós (acadêmicos) também ignorados, senão rechaçados, porque erráticos, "sem propósito" imediato, ou seja, sem acolhida em nossas expectativas e categorias de entendimento. Quando herdeiros da atenção à política de/da classe para a classe, como os Comaroff ou Taussig, ignoramos muito facilmente o que se passa fora do ambiente do trabal ho assalariado e da reivindicação sindical, corporativa. Ignoramos o trabalho das mulheres e jovens, como Bongiwe, cujo tempo, por uma questão lógica, ao ser empregado em outras coisas (por vezes em um emprego remunerado, mas normalmente em rituais não rentáveis), as torna invisíveis como seus afazeres e, consequentemente, indesejáveis para nós, quando cumprindo o papel de olhos do Estado, no interior dos muros acadêmicos (Lalu, 2019).

A transformação analítica que proponho tem a ver com esta lição política que me foi ensinada por essas pessoas que me receberam em suas pesquisas, minhas anfitriãs. Sua experiência da violência passa por um entendimento do capitalismo como veneno, como feitiço, contra o qual não há antídoto definitivo. A bruxaria envenena, mata. E o menosprezo à bruxaria explica o eterno retorno ao encontro colonial - ao momento fundacional em que europeus razoáveis encontram nativos irracionais e, em sua benevolência, dedicam-se ao seu aniquilamento - ou pelo extermínio ou por sua conversão em igual (Borges, 2013). Como sobreviver ao embruxamento, ao envenenamento? Graças a um discernimento que não é transcendente, alheio, superior. Pelo contrário, a condição de sobrevivência é o desembruxamento, que passa por um entendimento ritual de que sua existência não se reduz aos esquadrinhamentos do capital (Borges, 2020). Como bem sintetizam Pignarre e Stengers (2005), ao tempo que tal embruxamento não tem autoria precisa, há dedos de todas as mãos envolvidos nessa operação de destruição planetária. Voltando o ol har para perto, para a vida acadêmica, reconheçamos nossa ação (mormente por inação) na produção da dispensabilidade do diferente, a ponto de tirar-lhe a vida, ou seja, de produzirmos sua morte. Em suma, deixamos de ignorar a escravidão (e o racismo) na plantation do mundo acadêmico.

Para avançar, nesse sentido, seria correto afirmar que nós, devotos da democracia como realização transcendente, estaríamos mais próximos da morte por abdução (como zumbis) do que aqueles que lidam com o monstro todos os dias sem baixar a guarda, atentos para não sermos devorados. Mulheres como Bongiwe, "excluídas" do mercado, da universidade, da vida pública, são quem detêm conhecimento de como as coisas funcionam. Quem dentre nós ousaria dizer algo assim? Quem sabe como as coisas funcionam (na universidade, por exemplo)? Mesmo cientes da nebulosa que nos cerca, não pensamos duas vezes na hora de emitirjuízos sobre a alienação popular. Resumindo, nós que investigamos pouco, sedados que estamos, embruxados, é que somos O Problema. Essa constatação pode ser o primeiro passo para o desembruxamento. E é Bongiwe quem com ela nos brinda, quando nos oferece seu tempo. 


\section{NERVOUS CONDITION}

A figura evocada por Bongiwe do ser humano drenado, esvaziado, "zumbificado", é um dos vários motes que inspiram a artista zimbabuana Tsitsi Dangarembga, cujas obras de ficção serão por mim resgatadas para fazer considerações sobre o inabalável peso do fardo colonial e a relação dessa persistência com as estruturas de ensino superior como as temos no sul do continente africano ou, quiçá, no sul global $^{8}$. Retorno, para isso, ao tema da loucura, da insanidade, mais detidamente no contexto acadêmico. Para quem partiu de um Very Rural Background, o mínimo que se espera, o que se aconselha, como vimos, é não olhar para trás. Não é aceitável transitar, pois a metamorfose periódica torna sensível justamente esta incômoda ontologia combativa.

Tomemos Tambudzai Sigauke, personagem principal de Nervous Condition ${ }^{9}$ (Condição Nervosa), The book of Not (o Livro do Não) e This Mournable Body (Este corpo velável), uma trilogia da artista zimbabuana Tsitsi Dangarembga ${ }^{10}$. No primeiro romance, de 1988, acompanhamos sua vida na roça, sua árdua dedicação à horta que aprendeu a cultivar com sua avó, sua maestria na roça de milho, seus conflitos com o pai que privilegia seu irmão, as tímidas investidas em sua defesa por parte de sua mãe, as trapaças do mesmo irmão e sua morte, o que lhe abre a oportunidade de estudar na missão em que seu tio paterno atua; lá, seu convívio com a prima Nyasha, da mesma idade, mas com mente e corpo incapazes de aceitar tanto a experiência da Rodésia colonial como a dos anos que vivera na África do Sul e, posteriormente, na Inglaterra, durante o doutorado do pai.

Em The Book of Not, de 2006, a autora aborda a subsequente educação secundária de Tambudzai na Young Ladies College of the Sacred Heart, sua intensa e violenta ruptura com a roça, seus desapontamentos nos bicos que faz, nos pensionatos em que vive - tudo isso tendo como pano de fundo a guerra de independência (chimurenga). Sua irmã perde a perna na explosão de uma mina; sua mãe alcagueta o mesmo tio paterno que a educara, o qual é espancado até ficar aleijado - e sua condição sem precedentes de zimbabuana quando finda a Rodésia (Kennedy, 2008). Hoje, quando lemos o último romance da trilogia, publicado em 2018, aprendemos que Tambudzai terminou por estudar Sociologia na Universidade do Zimbábue, trabalhou em uma agência de publicidade, na qual teve suas ideias usurpadas pela proprietária branca, ex-colega do secundário, o que a leva ao fundo do poço, do qual se reergue mais vazia e dilacerada do que antes da queda.

Vivendo na capital, no pós-guerra, Tambudzai não se conecta com a roça ou com aqueles com quem conviveu na escola nos anos 1960 e 1970. A maioria branca de seus colegas já não mais vive no país. Os outros poucos que como ela concluíram o ensino superior estão em outros países, servindo mesas e trocando fraldas. Tampouco se conecta ou se identifica com aqueles que nunca adentraram os muros

\section{8|A partir de suas obras literária e cinematográfica, Tsitsi Dangarembga, nascida em 1959, tornou-se referência não somente incontornável para os estudos literários, mas voz politicamente inspiradora para as discussões sobre interseccionalidade (Makoni-Muchemwa, 2009) Ainda que a própria autora identifique muitas origens para suas obras, especialmente a trilogia iniciada com Nervous Condition é apontada pela bibliografia exegética como de caráter primordialmente biográfico (Zondi, 2013).}

9| Embora o título nos remeta à introdução de Sartre a Os condenados da Terra, de Fanon, onde se lê $A$ condição do nativo é uma condição nervosa introduzida e mantida pelo invasor com seu consentimento..., assume-se que Dangarembga só tenha lido Os Condenados da Terra após o término de Nervous Condition (Bhana, 1999).

10| A autora deste romance que se tornou uma referência constante nos debates feministas pós-coloniais teve em muitas entrevistas de responder a indagações sobre o romance que daria sequência à Nervous Conditions (Lee, 2006) Naquele então, não havia tal sequência, tal continuidade. 
acadêmicos, em especial os veteranos de guerra. Depois de muito vagar, esta mulher de meia-idade, desesperada, consegue no governo um emprego como professora de biologia, embora não tenha formação nesta área, em uma escola secundária para meninas. Quando de sua admissão, a diretora, que não esconde seu afã nacionalista, Ihe diz: [...] bom que você ainda está aqui e não na África do Sul ou na Europa ou mesmo em Botswana. Imagina isso, agora os zimbabuanos estão indo para esses lugarzinhos, como Zâmbia, alguns até optando por Moçambique ou Malawi. Tudo isso acontecendo a despeito da memória viva, no nosso pós-independência.

Tambudzai tem aversão à diretora, às estudantes que se dedicam aos seus celulares e às vontades de sugar daddies, mas a despeito disso, devota-se a dar excelentes aulas (Tiriba, 2019). No entanto, é incriminada por agredir fisicamente uma aluna e termina internada numa instituição que trata basicamente de conter as alucinações de brancos, idosos, traumatizados pela guerra. Submetida à contenção química, Tambudzai experimenta intensamente a presença de formigas que escalam seu corpo, enquanto escuta os guinchos estridentes de hienas que se burlam do patético fim que o destino Ihe reservou. Em suma, Tambudzai enlouquecera, assim como haviam sugerido a Bongiwe.

Quando recebe alta, vai morar com Nyasha. Somente chegando à casa da prima descobre que ela havia se casado com um alemão. Em uma das primeiras conversas, o marido da prima revela o suposto motivo da comiseração de sua esposa (Muponde, 2011). Tambudzai, como as jovens mulheres que fazem oficinas de reciclagem no pátio de sua casa, são meros Human Resources. Mesmo naquela casa que parecia acolhê-la, a existência de Tambudzai só seria tolerada caso servisse de fluido para o empreendimento de pequenas proporções e de pretensão humanitária que sua prima comandava ${ }^{11}$.

\section{COMPOSIÇÃO-TERRA}

Como alerta Matebeni (2017), o universo de intelectuais, do qual ela destaca ativistas LGBTQI+, obliterados pelos holofotes que realçam o intramuros universitário, tem proporções e importância que não devem ser negligenciados, sob pena de vermos ruir tudo: o que está dentro e o que está fora do castelo da educação dita superior. Para a autora, com a xenofobia e com o médio-classismo reitera-se a fronteira. Soma-se a esta aguda crítica aquela feita à redemocratização racista, que sublinha que não devemos nos contentar com vitórias parciais e estamentais e que é preciso seguir refutando a territorialidade colonial, os escaninhos onde se acomodam uns, separados de outros.

A tal respeito, é preciso que se aponte, na África do Sul de movimentos sociais no âmbito da universidade como \#rhodesmustfall, um mundo acadêmico paralelo, de makwerekweres, servindo mesas, limpando bunda de crianças. É certo que alguns

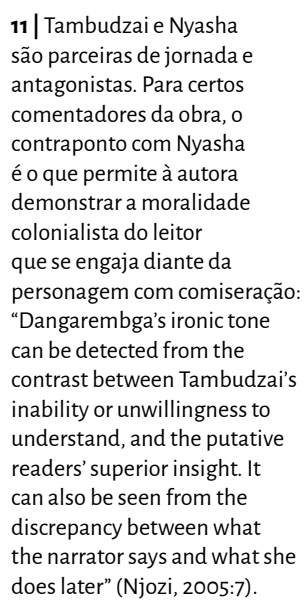


zimbabuanos adentram a universidade na África do Sul e alhures. Não é este meu ponto aqui. A questão é pensar, como nos alerta Matebeni (2017) e Nyamnjoh (2016), na contradição que há entre reivindicações dos manifestantes por horizontalidade antirracista e a persistente xenofobia e extração de mais-valia desses que são meros Human Resources, do outro lado da fronteira ou mesmo no interior do país.

Bongiwe se debruçava há muito sobre tais paradoxos. Antes de ter seu filho, antes de regressar ao vilarejo rural, quando ainda circulava pela plantation em Johanesburgo, Bongiwe observava o menosprezo ao seu sotaque, do qual ela procurava se desvencilhar mencionando a farm de seu avô, em alusão à fazenda que sua família recebera num processo de redistribuição de terras ${ }^{12}$. Acompanhou atentamente o crescendo dos movimentos estudantis pela descolonização da vida acadêmica sul-africana, sem jamais ser convidada para participar, sem jamais ter tido tempo livre para os efervescentes encontros conduzidos pelos estudantes mais privilegiados assim como Nyamnjoh, Bongiwe percebia limites nas propostas de descolonização que não desafiavam a composição-plantation da vida acadêmica. No entendimento de Bongiwe, ela, como era, não era bem-vinda na universidade de agora e tampouco o seria no futuro almejado pelos críticos ao colonialismo, que dela burlariam como as hienas de Tambudzai (Oaks, 1977; Elon Dancy Il et al., 2018; Squire et al. , 2018).

Neste ponto, torna-se incontornável mencionar a importância das reflexões sobre o Plantationceno (outro nome dado ao Antropoceno) para a teoria antropológica contemporânea (Haraway et al., 2015). Haraway é uma das mais destacadas e inspiradoras intelectuais a alimentar os debates sobre o tema. Sua crítica, ora chamada de pós-humanista, tem orientado mudanças nas composições do que se torna matéria de interesse etnográfico. Mais que combinar humanos e não humanos, Haraway almeja um tipo de parentesco $(k i n)$ que se rebele contra os entendimentos modernos de ancestralidade e genealogia (Haraway, 2016). A transformação analítica a que convoca está intimamente relacionada com a possibilidade de estender a política para os seres tidos como não políticos ou, para ser mais precisa, de retirar de todos a política, restituindo-os à comum condição de Earth Beings (La Cadena, 2015).

A inegável pertinência deste debate não o exime de limitações. Acadêmicos atentos à centralidade do racismo para o capitalismo apontam para as lacunas em termos heurísticos desta literatura dedicada à ontologia multiespecífica (Pulido, 2018). Em sua crítica, sugerem que argumentos afins aos de Haraway minimizam as lutas negras, pois não apostam na atenção à vida escravizada como inspiradora para o cultivo de múltiplos mundos (Davis et al., 2018). Reivindicam que foi em uma terra, nas imediações da plantation, mas muito além de seu escrutínio, que as pessoas escravizadas refutaram o modo como a violenta plantation procurava constituí-las unicamente como trabalho (King, 2016). A terra foi condição fundamental para a sua emancipação. Por causa da terra, para além do trabalho, viveram para um futuro, como anota McKittrick (2013), em seu argumento sobre um plantation future.
12 | Na África do Sul não houve expropriação de terras sem indenização, como no Zimbábue. Para o processo de redistribuição de terras que beneficia moradores de fazenda, como o era a família Khubeka, ver Rosa (2012). 
Ao rebater críticas de detratores do movimento estudantil, algumas nostálgicas, vindas de ativistas de esquerda que lutaram contra o apartheid, Gillespie \& Naidoo (2019) argumentam em favor do inusitado sentido político de suas ações. Para elas, os estudantes negros contestaram com suas subjetividades um projeto capitalista racista e estagnado. Minha crítica às autoras não contesta sua afirmação, mas tão somente aponta para seu caráter parcial diante das exclusões que ignoram, especialmente a exclusão da composição-terra de pessoas como Bongiwe, a exemplo do que nos ensinou Mafeje. Tomemos a composição-terra da África do Sul e de suas entranhas perscrutadas na extração mineral que se dá em meio ao esbulho territorial e todo o consequente esvaziamento que o acompanha. Para que as reivindicações indígenas por terra não façam sentido (econômico, especialmente) é preciso, sobretudo, invalidar o sentido existencial da relação com a terra, como o faziam os críticos do comportamento de Bongiwe. Sua composição-terra é e será sempre maldita: um corpo negro eivado de formigas em frenesi é, como observa Matebeni sobre o corpo queer, um corpo com coisas demais, um corpo sem foco, pouco dócil, trabalhoso para se explorar (Tiriba e Moutinho, 2017: 183). Nunca será o corpo negro esperado na luta anticolonial do fallism. Em suma, mesmo em experimentos de promoção da igualdade, a universidade reitera a perenidade da plantation ao rejeitar esses corpos com very rural background e sua ontologia.

A aproximação entre Bongiwe e Tambudzai me leva a cogitar a possibilidade de pensar o processo educativo como um esvaziamento, ao qual se segue um preenchimento com conteúdos que, entre outras propriedades, provocam nos sujeitos uma impossibilidade de se reconhecerem como parte de uma longa história, de se sentirem acompanhados. A universidade como plantation seria um dos lugares privilegiados para essa transformação dos corpos, para sua zumbificação. Certa literatura sobre a transformação por que passou a Educação Superior no Zimbábue traz hipóteses em sintonia com essas que me levam a aproximar Tambudzai (uma personagem de ficção) de Bongiwe (uma mulher sul-africana que conheço há tantos anos). Nesses escritos, há um investimento analítico na comparação da qualidade do engajamento dos estudantes universitários de seu país com os da África do Sul no pós-apartheid.

O Zimbábue tinha até 1980 apenas uma universidade, naquele ano com 2 mil alunos e hoje com 20 mil $^{13}$. Esta universidade pública abriu suas portas no início dos anos 1950 como The University College of Rhodesia and Nyasaland vinculada à University of London. Com bem menos de $1 \%$ de estudantes negros, era mantida financeiramente pelo Estado colonial britânico e atraía acadêmicos e estudantes de todo o antigo império britânico. Tornou-se Universidade da Rodésia em 1971, e

13 A partir dela, as demais instituições de ensino superior floresceram. Hoje, há 14 universidades públicas e dez privadas no país, com 100 mil alunos, segundo dados do Ministério da Educação Superior e Terciária, Ciência e Desenvolvimento Tecnológico. em 1980 a atual Universidade do Zimbábue. No pós-independência seguiu atraindo acadêmicos do mundo, engajados nas lutas socialistas e antirracistas.

Para Moyo e Yeros (2007), o processo de reforma agrária chamada de "acelerada" (fast-track), como conduzida no Zimbábue a partir do ano 2000, era apontado como caótico e anárquico por uma literatura desenvolvimentista exclusivamente 
interessada na produção de commodities agrícolas. Para os autores, no entanto, faz-se imperioso estudar os efeitos da ocupação de terras e da expropriação de latifúndios pelo Estado na transformação das formas de participação política em nível local e das mentalidades na pós-colônia. A mesma ressalva é feita a respeito da experiência universitária no país. Há os que chamam atenção para a universidade como um balão de ensaio revelador para experimentos de grande impacto naquele país, como as políticas de ajuste estrutural, o movimento dos veteranos de guerra e o programa de reforma agrária. No entanto, onde alguns identificam apenas perda de status e de qualidade, dada a dilapidação da infraestrutura acadêmica (Mhlanga, 2008:322), outros indicam paisagens propícias para que vozes outrora silenciadas se façam ouvir: justamente as vozes daqueles com very rural background (Chikwanha, 2009).

Ao passo que no país vizinho os movimentos de estudantes conhecidos como fallism clamam por uma descolonização epistêmica da universidade, contínuas greves de docentes e protestos de estudantes têm ocorrido no Zimbábue ao menos desde 1989, e as pesquisas atentas aos rearranjos cotidianos em uma paisagem de outra forma desprezível, porque devastada para o capital, indicam que estudantes no Zimbábue há muitos anos indicam os danos políticos do encastelamento acadêmico de cariz colonial e sua relação com a produção de uma clivagem interna que deveria igualmente ser posta à prova em face das bandeiras da decolonialidade (Zembere, 2018). Segundo tais argumentos, especialmente a Universidade do Zimbábue viveu no pós-independência os dilemas de se orgulhar de uma herança, a excelência acadêmica, da qual deveria se envergonhar - o legado colonial. Ao longo desses anos, o que era um modelo baseado na excelência acadêmica e no suporte financeiro estatal foi se esfacelando, ao passo que o ingresso de zimbabuanos foi crescendo. Diante da diminuição de investimentos internacionais, o fardo recaiu sobre os estudantes, muitos deles com um very rural background (Chikwanha, 2009).

Reiteradamente, em vários âmbitos de sua existência, o país viu aqueles marcados por sua composição-terra sendo contestados por seu discurso decolonizador de menor estardalhaço, por vezes vendo suas reivindicações indígenas tomadas como tendências neoliberais (Garwe e Thondhlana, 2019). É o que Dangarembga sublinha com Tambudzai. Ela é uma doutora em Sociologia que ingressa no mercado, não porque almeje suas benesses, mas porque se impacienta com a acomodação cordata da academia, das ONGs. O mundo da agência de propaganda dirigida por sua colega de adolescência branca é mais gritantemente racista e, por isso, nele ela está constantemente atenta. Nele, sua qualificação como mero Human Resource, embora a revolte, não a surpreende.

Tomemos a composição-terra de Tambudzai ao ser perscrutada por formigas, constituída como um ser com formigas, torturada por experimentar o que na escola tinha aprendido não existir - alucinações (Toda, 2009). Não se trata de dizer que Tambudzai é o Zimbábue, mas de afirmar que o Zimbábue, assim como Tambudzai, é 
terra e que a recusa acadêmica em aceitar e dar boas-vindas à composição-terra das pessoas ou de qualquer fenômeno equipara-se à classificação do outro — pessoa ou país - como meros (Human) Resources. Ao fim do romance, Tambudzai retoma os contatos com Tracy, sua colega branca de secundário, que se torna novamente sua patroa, desta feita, construindo uma eco village (chamada Creen Jacaranda, esta espécie do chamado novo mundo que colore as alamedas coloniais em todo o planeta) em sua aldeia natal, a fim de prover turistas europeus com algo genuíno - a vida na roça ou o very rural background de que tanto tentou se livrar. Remoída de vergonha, Tambudzai foge de lá no dia da inauguração do resort de pau a pique, inconsolável por ter conduzido as mulheres de sua família, incluindo sua velha mãe, a dançar com o torso nu, para o deleite dos europeus, em frenesi com suas câmeras fotográficas (Shange, 2020).

A fragmentação colonial, que Depelchin (2011) equipara ao bombardeio nuclear do continente, é muito frequentemente repetida no cotidiano acadêmico, a despeito da boa causa em nome da qual se realiza - seja a ciência ou o desenvolvimento. A experiência radicalmente distinta da vida universitária em países como a África do Sul e o Zimbábue deve ser por nós levada a sério, sobretudo para ponderar sobre o quanto de consentimento há, de nossa parte, na constante produção de condições nervosas ou de neuroses no que nos habituamos a chamar de período democrático ou pós-colonial.

\section{CONCLUSÃO}

As experiências de Bongiwee de Tambudzai revelam certa política sem nenhum crédito, feita fora dos fóruns estabelecidos e dos debates de conjuntura levados a cabo por quem tem seu sustento garantido por outras fontes (como nós, diga-se de passagem, tão assíduos nos ambientes do chamado fallism). Ademais, no geral, trata-se de uma política que produz por vias negativas, ou seja, por não fazer alguma coisa, mas impedindo que coisas daninhas sejam feitas (como Bongiwe e seu pedido de demissão da Mango ou a fuga de Tambudzai do Creen Jacaranda). Essa alteração nas demandas e nas predileções - porque nascida de experiência autônoma — raramente é reconhecida como legítima pela dificuldade de narrá-las em termos reconhecidos pelo Estado, pela Ciência, pela Academia, pelo Capital. Elas foram da roça para a cidade e retornaram, enada diz que a ela não regressarão. Se seguirem vivas como pretendem, jamais estarão contidas aqui ou ali em um espaço esquadrinhado. Opõem-se à morte na plantation sem memória com a vida de sua composição-terra ancestral e futura.

A reflexão sobre tudo o que se passa na vida para além da composição-plantation, para o que se passa entre zero e um, entre servir como human resource ou ser dispensável, nos leva a afirmar que nossa indiferença em relação ao que é comezinho, cotidiano, crônico e ordinário assemelha-se à indiferença estatal que produz a inexistência de tudo aquilo em que não se presta atenção ${ }^{14}$. Temos uma tendência a estudar e dar ênfase a facetas dos sujeitos que nos são inteligíveis justamente porque os pensamos,

14 | Pignarre e Stengers (2005) reúnem na fórmula "faire attention" (prestar a devida atenção) uma reflexão sobre a prática analítica e política que seria antídoto ao embruxamento capitalista. A orientação é metodológica e política, como alertam igualmente Ndebele (2006) e Das (2006) com sua proposta de redescoberta do ordinário. 
os enquadramos como Estado, ou seja, pela falta, pelo que eles e elas não podem. Além disso, a falta dialoga com dois temas caros à democracia, ainda que, no limite, paradoxais: a igualdade e o direito à diferença. Lamentamos a falta porque acreditamos sermos iguais. Nesta chave, não é justo que lhes falte discernimento, comida, utopias, se nós as temos de sobra. Por outro lado, o Outro assim definido garante a segregação, como advertem Nyamnjoh (2016) e Mbembe (2019), entre outros. Esses autores se esforçam politicamente para afirmar que os contornos precisos e as naturezas perenes exigidos pelo colonialismo (de hoje e de ontem) ignoram formações sociais que tomam de empréstimo e se transformam constantemente, precisando do Outro, justamente na sua diferença, para sua constituição plástica; necessitando, portanto, da diferença, e não de seu extermínio. Na esteira das preocupações de Fanon e Mafeje, aventam uma possibilidade de futuro na transformação e não na repetição.

Nesta esteira, que existência teríamos nós se passássemos a prestar atenção ao que se tornou desprezível, dispensável, como o fizeram Bongiwe e Tambudzai, ao perceberem a armadilha dos embusteiros que as queriam esvaziadas, sem terra, sem sua composição-terra? Especialmente nós que nos dizemos acadêmicos, intelectuais, cientistas, por qual transformação passaríamos se nos déssemos conta de tudo o que nos passou despercebido, que dispensamos por sua irrelevância? É preciso notar que o engajamento de quem não está organizado de maneira reconhecível, isto é, de quem não segue um movimento, mas como diz Ailton Krenak (2019), movimenta-se, é muito facilmente desprezado pornós. Ou considerado uma ameaça. Trata-se de movimentos incertos - porque nem zero, nem um. Nesse sentido, torna-se possível afirmar que os desprezíveis e os desejáveis na democracia capitalista o são também no mundo da plantation acadêmica, temerosa diante da invasão do "produtivo" latifúndio colonial.

$\mathrm{Na}$ África do Sul, no Zimbábue e em todos os países onde as instituições ditas públicas, dedicadas à educação superior, precisem ser consideradas produtivas, a partir de um crivo único, global, as universidades terminarão, tal como numa plantation, por aniquilar modos de existência que não sejam rentáveis, isto é, corpos que não sejam dóceis ao capital. Aniquilar terminantemente não difere muito de arquitetar planos para que futuramente haja lugar para todos na plantation. A perenidade e a irrefutável pertinência do ponto de vista privilegiado realizam-se tanto na exclusão atual quanto nessa inclusão por vir, quando todos se realizarão como iguais porque serão o mesmo. Quando isso ocorrer não haverá mais necessidade de muros. Porém, enquanto isso não ocorre, melhor erguermos grades, cercas elétricas, câmeras, armas, vestibular, acreditando que somente o Outro indesejável está sendo aniquilado e não a composição-terra de toda a humanidade.

Ao invés de abdicar do tempo presente ou colocá-lo entre parênteses, deixando de lado as agruras que nos constituem, em nome de um quadro idílico por vir, sugiro que encaremos essa atitude como nefasta em si, uma atitude higienizadora, no limite, uma atitude de genocídio em que limpamos o mundo dos inconvenientes, dos 
que ao nosso gosto são desprezíveis, em nome da elaboração — em pensamento, por ora, como acreditamos - do mundo como ele deveria ser. Em suma, pensemos no que impedimos quando ficamos parados na fronteira, em cima do muro, como um guarda de aduana, reiterando a pertinência dos conceitos de alteridade e igualdade, para com eles podermos nos dedicar com indiferença à diferença. Não impedimos somente a liberdade de Bongiwe ou Tambudzai; impedimos a nossa própria liberdade.

\section{AGRADECIMENTOS}

Pelos debates que inspiraram os argumentos deste artigo e sob pena de esquecer importantes interlocutores, agradeço a Beatrice Mtetwa, Catarina Morawska, Divine Fuh, Eliane Veras, Femke Brandt, Giovanna Isis Castro Alves de Lima, Iracema Dulley, Jacques Depelchin, Laura Moutinho, Lauren Paremoer, Lungisile Ntsebeza, Luiz Ricardo de Souza Prado, Maíra Vale, Marcelo Rosa, Paris Yeros, Pauline Wynter, Paulo Neves, Remo Mutzenberg, Richa Nagar, Stella Paterniani (e todes es gestantes), Susana Durão e Walter Chambati.

Antonádia Borges é Professora no Departamento de Antropologia da Universidade de Brasília (UnB).

FINANCIAMENTO: Pelo apoio financeiro para garantir a consecução das pesquisas, menciono o importante fomento da CAPES e do CNPq.

CONTRIBUIÇÃO DE AUTORIA: Não se aplica.

\section{REFERÊNCIAS BIBLIOGRÁFICAS}

BHANA, Hershini. 1999. "The Condition of the native: autodestruction in Dangarembga's Nervous Conditions". Alternation, v. 6: 117-137.

BONILLA, Yarimare ROSA, Jonathan. \#Ferguson: Digital protest, hashtag ethnography, and the racial politics of social media in the United States. American Ethnologist, v. 42 (1), pp. 4-17.
BORGES, Antonádia. 2011. "Sem sombra para descansar: etnografia de funerais na África do Sul contemporânea". Anuário Antropológico, 2010, pp. 215-252.

BORGES, Antonádia. 2013. "Ser embruxado: notas epistemológicas sobre razão e poder na antropologia". Civitas. Revista de Ciências Sociais, 12(3): 469-488. 
BORGES, Antonádia, COSTA, Ana; BELISÁRIO, Gustavo, CIRNE, Michelle; LIMA, Natascha; VIANA, Talita e PATERNIANI, Stella. 2015. "PósAntropologia: as críticas de Archie Mafeje ao conceito de alteridade e sua proposta de uma ontologia combativa". Sociedade e Estado, v. 30: 347-369.

BORGES, Antonádia. 2017. "Cães e preconceito na África do Sul: um diálogo entre literatura e etnografia". Horizontes Antropológicos, v.23: 225-252.

BORGES, Antonádia. 2018. "Ethnographic Alliance: Hope and Knowledge Building through a South African Story". In: LAWSON, Victoria \& ELWOOD, Sarah. (Orgs.). Relational Poverty Politics: Forms, Struggles, and Possibilities. Athenas, University of Georgia Press, pp. 183-200.

BORGES, Antonádia. 2020. "Land as Home in South Africa: The Living and the Dead in Ritual Conversations". Agrarian South: Journal of Political Economy. No prelo.

CHERKI, Alice. 2016. "Fanon au temps présent. L'assignation au regard". Politique africaine, v.3(143): 145-152.

CHIKWANHA, Annie Barbara. 2009. "Zimbabwe". In: CHIMANIKIRE, Donald P (ed.) Youth and Higher Education in Africa: The Cases of Cameroon, South Africa, Eritrea and Zimbabwe. Dakar, Codesria, pp. 79-107

COMAROFF, Jean L., \& COMAROFF, John. 1987. "The madman and the migrant: Work and labor in the historical consciousness of a South African people". American Ethnologist, v. 14(2): 191-209.

COMAROFF, Jean L., \& COMAROFF, John. 1999. "Alien-Nation: Zombies, Immigrants, and Millennial Capitalism". Codesria Bulletin, n. 3/4 :17-28.
DAVIS, Janae; MOULTON, Alex; VAN SANT, Levi; WILLIAMS, Brian;. 2018. "Anthropocene, Capitalocene... Plantationocene?: A Manifesto for Ecological Justice in an Age of Clobal Crises". Geography Compass, n. 13(5): pp 01-15.

DAS, Veena. 2006. Life and Words. Violence and the Descent into the Ordinary. Berkeley, University of California Press.

DEPELCHIN, Jacques. 2011. Reclaiming African History. Bangalore, Pambazuka Press.

DERRIDA, Jacques. [1995] 2008. Mal d'archive. Une impression freudienne. Paris, Galilée.

DONHAM, Donald L. 2011. Violence in a Time of Liberation: Murder and Ethnicity at a South African Cold Mine, 1994. Durham, Duke University Press.

ELON DANCY II, T.; EDWARDS, Kirsten e DAVIS, James. 2018. "Historically White Universities and Plantation Politics: Anti-Blackness and Higher Education in the Black Lives Matter Era". Urban Education, v. 53(2): 176-195.

FANON, Frantz. [1961] 1968. Os condenados da terra. Rio de Janeiro, Civilização Brasileira.

GARWE, Evelyn Chiyewo e THONDHLANA, Juliet 2019. "Higher Education Systems and Institutions, Zimbabwe". In JUNG-CHEOL Shin e TEIXEIRA, Pedro Nuno (eds.) Encyclopedia of International Higher Education Systems and Institutions. Dordrecht: Springer. n.p.

GILLESPIE, Kelly e NAIDOO, Leigh-Ann. 2019. "Between the Cold War and the Fire: The Student Movement, Antiassimilation, and the Question of the Future in South Africa". The South Atlantic Quarterly, v. 118(1): 226-239. HARAWAY, Donna ] . 2016. Staying with the trouble: Making kin in the Chthulucene. Durham, Duke University Press. 
ARTICo|Antonádia Borges | Very Rural Background: os desafios da composição-terra

HARAWAY, Donna; ISHIKAWA, Noburo; GILBERT, Scott; OLWIG, Kenneth; TSING, Anna e BUBANDT, Nils. 2015. "Anthropologists are talking. About the Anthropocene". Ethnos, v. 81(3): 535-564.

JANSEN, Jonathan. 2017. As by fire. The End of the South African University. Cape Town, Tafelberg.

KENNEDY, Rosanne. 2008. "Mortgaged Futures: Trauma, Subjectivity, and the Legacies of Colonialism in Tsitsi Dangarembga's The Book of Not". Studies in the Novel, v. 40(1-2): 86-107.

KILOMBA, Grada. 2008. Plantation Memories. Episodes of Everyday Racism. Münster, Unrast.

KING, Tiffany Lethabo. 2016. "The labor of (re) reading plantation landscapes fungible(ly)". Antipode, v. 48: 1022-1039.

KRENAK, Ailton. 2019. Ideias para adiar o fim do mundo. São Paulo, Companhia das Letras.pp.

LA CADENA, Marisol de. 2015. Earth beings, ecologies of practice across Andean worlds. Durham, Duke University Press.

LALU, Pramesh. 2019. "What Is the University For?". Critical Times, n. 2(1): 39-58.

LEE, Christopher Joon-Hai. 2006.

"Desperately Seeking Tsitsi: A conversation with Tsitsi Dangarembga". Transition, v,13: 128-150.

MABIN, Alan. 1991. "The dynamics of urbanisation since 1960”. In: SWILLING, Mark; HUMPHRIES, Richard e SHUBANE, Khehla (eds.) Apartheid City in Transition. Oxford University Press, Cape Town: Oxford University Press. pp.33-47.
MAFEJE, Archie. 1962. "A chief visits town". Journal of Local Administration Overseas, v. 2: 88-99.

MAFEJE, Archie. 1967. "The role of the bard in a contemporary African community". Journal of African Languages, v. 6(3): 193-223.

MCKITTRICK, Katherine. 2013. "Plantation futures". Small Axe: A Caribbean Journal of Criticism, v. 17(3): 01-15.

MAKONI-MUCHEMWA, Upenyu. 2009. "How can you be balanced at the moment of unhinging? Interview with Tsitsi Dangarembga". Disponível em: http://archive.kubatana. net/html/archive/artcul/090805inzwa3. asp?sector=gen\&year=2009\&range_start=31. Acesso em: 26 de outubro de 2020.

MATEBENI, Zethu. 2017. "Perspectivas do Sul sobre Relações de Gênero e Sexualidades: Uma Intervenção Queer". Revista de Antropologia, v. 60 (3): 26-44.

MATORY, J Lorand. 2018. The Fetish Revisited: Marx, Freud, and the Cods Black People Make. Durham, Duke University Press.

MBEMBE, Achille. 2019. "Future Knowledges and their implications for the decolonisation project". In: Jansen, Jonathan D. (ed.). Decolonisation in Universities. The Politics of Knowledge. Johannesburg, Wits University Press. pp. 239-254.

MHLANCA, Ephraim. 2008. Quality Assurance in Higher Education in Southern Africa: The Case of the Universities of the Witwatersrand, Zimbabwe and Botswana. Johannesburg, tese de doutorado. University of the Witwatersrand.

MOUTINHO, Laura. 2019. "Cooperação internacional, parcerias acadêmicas e afeto na perspectiva Sul-Sul". Revista Estudos Feministas, Florianópolis, v. 27(3): , e67310 
MOYO, Sam. 2011. "Land concentration and accumulation after redistributive reform in post-settler Zimbabwe". Review of African Political Economy, v. 38(128): 257-276.

MOYO, Sam e YEROS, Paris. 2007. "The Radicalised State: Zimbabwe's. Interrupted Revolution". Review of African Political Economy, v. 34(111): 103-121.

MUPONDE, Robert. 2011. "I am well if you are well': nervous conditions of African philanthropy in Tsitsi Dangarembga's novels". African Identities, v.9(4): 387-400.

NDEBELE, Njabulo. 2006. Rediscovery of the Ordinary. Essays on South African Literature and Culture. Scottsville: University of KwaZulu-Natal Press.

NEVES, Paulo Sérgio da Costa; MOUTINHO, Laura; SCHWARCZ, Lilia Katri Moritz. 2019. "Herança colonial confrontada: reflexões sobre África do Sul, Brasil e Estados Unidos". Revista Estudos Feminista, Florianópolis, v. 27 (3): e66960

NJOZI, Hamza Mustafa. 2005.

"Utilitarianism versus Universalism in Dangarembga's Nervous Conditions". Nordic Journal of African Studies. v. 14 (1): 1-14.

NTSEBEZA, Lungisile. 2005.

Democracy Compromised: Chiefs and the Politics of the Land in South Africa. Leiden and Boston: Brill. 326p.

NTSEBEZA, Lungisile. 2016). "What Can We Learn from Archie Mafeje about the Road to Democracy in South Africa?"'. Development and Change, v. 47(4): 918-936.

NYAMNJOH, Francis. 2016. Rhodes Must Fall: Nibbling at Resilient Colonialism in South Africa. Bamenda, Langaa Research and Publishing Common Initiative.
OAKS, Dallin.1977. "Universities as Government Plantations". Learning and the Law, v. 4(1): 20-51.

PEREIRA, Luena. 2016. "Feitiçaria e esfera pública: Estado e cultura no pós-guerra angolano". Sankofa, v. 9(16):135-161.

PIGNARRE, Philippe e STENCERS, Isabelle. 2005. La sorcellerie capitaliste. Pratiques de désenvoûtement. Paris, La Découverte.

POVINELLI, Elizabeth. 2011. Economies of Abandonment: Social Belonging and Endurance in Late Liberalism. Durham, Duke University Press.

PULIDO, Laura. 2018. "Racism and the Anthropocene". In: Mitman, Gregg; Armiero, Marco e Emmett, Robert (org..) Future remains: $A$ cabinet of curiosities for the Anthropocene. Chicago, University of Chicago Press. pp. 116-128.

ROSA, Marcelo. 2011. "Mas eu fui uma estrela do futebol! As incoerências sociológicas e as controvérsias sociais de um militante semterra sul-africano". Mana, v. 17(2): 365-394.

ROSA, Marcelo. 2012. "A terra e seus vários sentidos: por uma sociologia e etnologia dos moradores de fazenda na África do Sul contemporânea". Sociedade e Estado, v. 27(2): 361-385.

Shange, Kholela. 2020. “Sixosh' abathakathi: Ukuthwebula and the photographic image". Disponível em: [https://mg.co.za/ friday/2020-02-18-sixosh-abathakathiukuthwebula-and-the-photographicimage/]. Acesso em 26 de outubro de 2020

SQUIRE, Dian; WILLIAMS, Bianca e TUITT, Frank. 2018. "Plantation Politics and Neoliberal Racism in Higher Education: A Framework for Reconstructing Anti-Racist Institutions". Teachers College Record (120), Columbia University, 2op. 
TAUSSIG, Michael. 1980. The devil and commodity fetishism in South America. Chicago, The University of Chicago Press.

TIRIBA, Thais. 2019. "Sugar relationships: sexo, afeto e consumo na África do Sul e no Brasil". Revista Estudos Feministas, v.27(3): e66921.

TIRIBA, Thais e MOUTINHO, Laura. 2017. "Olhares compartilhados": (des) continuidades, interseccionalidade e desafios da relação Sul-Sul. Entrevista com Zethu Matebeni. Revista de Antropologia, 60(3): 181-185. https://doi. org/10.11606/2179-0892.ra.2017.141743
TODA, Yukiko. 2009. "Images of Queen Bee/Ant/Termite and Female 'Selfhood': Sylvia Plath, Alice Walker, and Toni Morrison." Cengo to Hyogen (Journal of Language and Expression), v. 5: 11-24.

ZEMBERE, M. 2018. Democratic citizenship education in Zimbabwe's higher education system and its implications for teaching and learning. Stellenbosch, tese de doutorado, Stellenbosch University. ZONDI, Nompumelelo. 2013. "Position of Women in Zulu and Shona Societies: The Case of Uvalo Lwezinhlonzi and Nervous Conditions". Alternation, v. 20(2): 164-182.

Recebido em 4 de maio de 2020. Aceito em 10 de junho de 2020. 